\title{
A Novel Technique for Rotor Bar Failure Detection in Single-Cage Induction Motor Using FEM and MATLAB/SIMULINK
}

\author{
Seyed Abbas Taher ${ }^{1}$ and Majid Malekpour ${ }^{2}$ \\ ${ }^{1}$ Department of Electrical Engineering, Faculty of Engineering, University of Kashan, \\ Kashan 87317-51167, Iran \\ ${ }^{2}$ Sama Technical and Vocational Training College, Islamic Azad University, Yasuj Branch, Yasuj, Iran \\ Correspondence should be addressed to Seyed Abbas Taher, sataher@kashanu.ac.ir
}

Received 14 June 2011; Revised 10 September 2011; Accepted 12 September 2011

Academic Editor: Wei-Chiang Hong

Copyright (C) 2011 S. A. Taher and M. Malekpour. This is an open access article distributed under the Creative Commons Attribution License, which permits unrestricted use, distribution, and reproduction in any medium, provided the original work is properly cited.

In this article, a new fault detection technique is proposed for squirrel cage induction motor (SCIM) based on detection of rotor bar failure. This type of fault detection is commonly carried out, while motor continues to work at a steady-state regime. Recently, several methods have been presented for rotor bar failure detection based on evaluation of the start-up transient current. The proposed method here is capable of fault detection immediately after bar breakage, where a threephase SCIM is modelled in finite element method (FEM) using Maxwell2D software. Broken rotor bars are then modelled by the corresponding outer rotor impedance obtained by GA, thereby presenting an analogue model extracted from FEM to be simulated in a flexible environment such as MATLAB/SIMULINK. To improve the failure recognition, the stator current signal was analysed using discrete wavelet transform (DWT).

\section{Introduction}

Induction motors (IMs) play an important role in many industrial processes. Hence, IM failures should be detected at early stages before they become catastrophic and lead to shutdowns and enhanced maintenance costs. Condition monitoring is desirable for increasing machinery availability, reducing consequential damage, and improving operational efficiency [1-3]. IM faults may occur in three main parts of the machine; stator, rotor, and bearings. Rotor bars are commonly broken in squirrel cage induction motor (SCIM) due to several causes [4, 5], including (1) thermal stress, (2) magnetic stress, (3) residual stresses from manufacturing, (4) dynamic stress from shaft torques, (5) mechanical stress owed to bearing failure, and (6) environmental stresses such as moisture. 
In terms of condition monitoring, fault detection in SCIM is studied in two categories; steady-state condition and during start-up transient condition. For many years, researchers have focused on fault detection methods which are based on steady state such as FFT. Recently, following progress in signal processing, methods based on study of the startup transient current have attracted attention. Traditional methods for monitoring the rotor conditions are based on frequency domain analysis of stator currents [6,7], mechanical vibrations [8], fluxes on search coils [9], and rotor speed [10] in steady state. Motor current signature analysis (MCSA) is used by many researchers due to its availability and simplicity. The broken bars induce some harmonic components with special frequencies in stator currents (sideband frequencies), as below

$$
f_{\mathrm{bb}}=(1 \pm 2 k s) f, \quad k=1,2, \ldots,
$$

where $s$ is the slip and $f$ is the supply frequency. Bar breakage occurs when the difference between the amplitude of fundamental frequency and the left sideband component is less than $50 \mathrm{~dB}$ [11]. The frequency analysis such as FFT, STFFT and recently multiple signal classification (MUSIC) and zoom-MUSIC are appropriate techniques to detect the sideband frequencies in stator current spectrum [12]. Figure 1 shows how STFFT is able to diagnose the broken bars in a full-load IM. The main drawbacks to STFFT [13] include (1) load dependence of the approach and (2) false diagnosis caused by ball bearing faults and voltage/load fluctuations. Many researchers have tried to improve the diagnosis by introducing a new criterion [14] or using such higher-frequency components as fault indicators which are not affected by load [15]. In the last few years, start-up transient current has been studied considering the progress made in signal processing techniques. Burnett et al. [16] and Watson and Paterson [17] have shown the superiority of the wavelet decomposition over other signal processing techniques for analysing the nonstationary signals. Discrete wavelet transform (DWT) is used by [18] who has suggested that "the frequency of the left sideband varies within a wide range during the start-up process and its amplitude reaches values that are several times higher than those in a stationary regime, and this is true for any load condition." The evolution of some frequencies allows the diagnosis and identification of broken rotor bars in IM during the startup transient. According to the frequency of sideband harmonic (i.e., $f_{L}=(1-2 s) f$ ), when the motor is switched on $(s=1)$, the left sideband component is equal to supply frequency. However, $f_{L}$ becomes $0 \mathrm{~Hz}$ when slip is reached half its value, and when the speed increases, the slip drops and $f_{L}$ almost reaches again the supply frequency [18]. This approach needs a minimum start-up time to avoid the electromagnetic transient which occurs immediately after start-up and masks the left sideband component [19].

An efficient condition monitoring system should be able to detect and use measurements taken immediately after fault occurs. This is because detection of potentially catastrophic faults in incipient stages prevents large power and production losses and also reduces maintenance costs. In this study, a fault detection system in SCIM is developed by assuming that a bar is suddenly broken, while SCIM operates in a steady state. Providing that the fault is not diagnosed at its early stages, fault will propagate towards the adjacent bars, causing local hot spots and interbar currents to appear leading to further damage to the magnetic circuit. Diagnosis of the fault in the incipient steps is the key solution to control and protect the SCIM. The developed diagnosis system here detects broken rotor bars immediately after breakage at rated value condition. However, the study of broken bars 


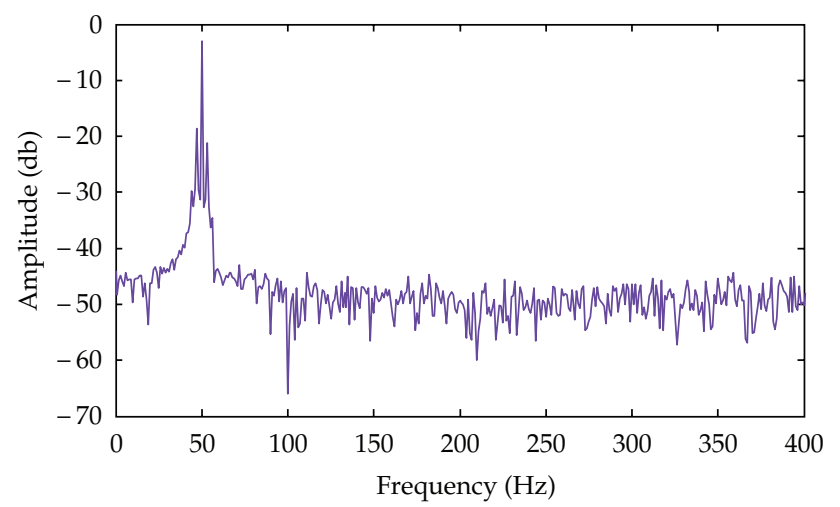

Figure 1: Frequency spectrum of stator current for rotor broken bar case in full load.

immediately after breakage cannot take place in reality, due to lack of access to the rotor during the operation of SCIM.

\section{SCIM Analysis Using Finite Element Method}

An effective diagnosis method requires an accurate and reliable SCIM model capable of revealing accurately the behaviour of the machine. Within the last few decades, FE method (FEM) has proved itself as an accurate and inexpensive technique for SCIM analysis by modelling material properties, nonlinearity, and complex structures of the machine such as rotating parts [20,21]. In this regard, FE simulation has provided a powerful tool as well as a good benchmark to study faulty machine behaviours, by comparing the available monitoring techniques and signal processing methods devised for this purpose. However, despite FEM capability for accurate modelling of SCIM through the well-known Maxwell's equations, it requires an extensive computational time due to the involved geometrical complexities of machine parts.

Principles of symmetry are employed wherever possible on machine parts to reduce the computation time. However, in the case of broken bars, this cannot be carried out due to asymmetric magnetic fields imposed by the fault. Therefore, to ensure the correct magnetic field distribution, the whole machine cross-section should be analysed. SCIM specifications required for this study are presented in Table 1 . Figure 2 shows the whole cross-section of the simulated SCIM in the Maxwell2D [22, 23], supplied by a symmetrical three-phase sinusoidal source with the stator windings in each of the three phases having identical turn number $(N=180)$. Various sections of the machine are divided into small parts by mesh nodes as illustrated in Figure 3 for rotor bars, air gap, and stator slots. The FE program Maxwell2D is used here to evaluate the influence of the broken rotor bar (BRB) fault on motor performance and generate virtual data in an accurate and cheap manner.

\section{Broken Rotor Bars Modelling}

Proper modelling of broken bars is needed for accurate and reliable diagnosis. In this context, resistance of the broken bar is assumed to be as large as possible in the FEM, considering the fact that in reality there is an interbar current among bars, leading to increased Joule losses in the adjacent bars. Furthermore, distribution of flux lines around the broken bars is changed. 
Table 1: Characteristics of the studied induction motor.

\begin{tabular}{|c|c|}
\hline \multicolumn{2}{|c|}{ 3-phase squirrel cage induction motor } \\
\hline Rated power & $5.5 \mathrm{KW}$ \\
\hline Supply frequency & $60 \mathrm{~Hz}$ \\
\hline Synchronous speed & $1800 \mathrm{rpm}$ \\
\hline Line supply voltage & $460 \mathrm{~V}$ \\
\hline Power factor & 0.87 \\
\hline Efficiency & 0.83 \\
\hline Winding connection & WYE \\
\hline Number of rotor slots & 26 \\
\hline Number of stator slots & 36 \\
\hline Outer diameter of stator & $190 \mathrm{~mm}$ \\
\hline Inner diameter of stator & $111.4 \mathrm{~mm}$ \\
\hline Length of stator core & $131.24 \mathrm{~mm}$ \\
\hline Stacking factor of stator core & 0.92 \\
\hline Type of steel (stator and rotor) & M19-24G \\
\hline Number of conductors per slot & 30 \\
\hline Wire wrap thickness & $0.107 \mathrm{~mm}$ \\
\hline Coil pitch & 9 \\
\hline Wire diameter & $1.15 \mathrm{~mm}$ \\
\hline Net slot area & $149.251 \mathrm{~mm}^{2}$ \\
\hline Stator current density & $9.27963 \mathrm{~A} / \mathrm{mm}^{2}$ \\
\hline Wire resistivity & $0.0217 \mathrm{Ohm} \cdot \mathrm{mm}^{2} / \mathrm{m}$ \\
\hline Air gap & $0.175 \mathrm{~mm}$ \\
\hline Inner diameter of rotor & $36 \mathrm{~mm}$ \\
\hline Length of rotor & $131.24 \mathrm{~mm}$ \\
\hline Stacking factor of rotor core & 0.92 \\
\hline Skew width & 0.9949 \\
\hline Height of end ring & $21.4093 \mathrm{~mm}$ \\
\hline Width of end ring & $11.4465 \mathrm{~mm}$ \\
\hline Rotor bar current density & $4.19715 \mathrm{~A} / \mathrm{mm}^{2}$ \\
\hline Rotor ring current density & $2.94869 \mathrm{~A} / \mathrm{mm}^{2}$ \\
\hline Resistivity of rotor bar (at $75^{\circ} \mathrm{C}$ ) & $0.0434783 \mathrm{Ohm} \cdot \mathrm{mm}^{2} / \mathrm{m}$ \\
\hline Resistivity of rotor ring $\left(\right.$ at $\left.75^{\circ} \mathrm{C}\right)$ & $0.0434783 \mathrm{Ohm} \cdot \mathrm{mm}^{2} / \mathrm{m}$ \\
\hline Skew width & 0.9949 \\
\hline Type of rotor bar & Cast aluminium \\
\hline Insulation class & $\mathrm{F}$ \\
\hline Temperature rise & Class B \\
\hline Protection degree & IP55-IC411 \\
\hline Stator resistance & $1.82583 \mathrm{ohm}$ \\
\hline Stator leakage inductance & $0.00738598 \mathrm{H}$ \\
\hline Rotor resistance referred to the stator & $1.25591 \mathrm{ohm}$ \\
\hline Rotor leakage inductance referred to the stator & $0.00705748 \mathrm{H}$ \\
\hline Magnetizing inductance & $0.1972858 \mathrm{H}$ \\
\hline Inertia & 0.15 \\
\hline Friction factor & 0.002 \\
\hline
\end{tabular}




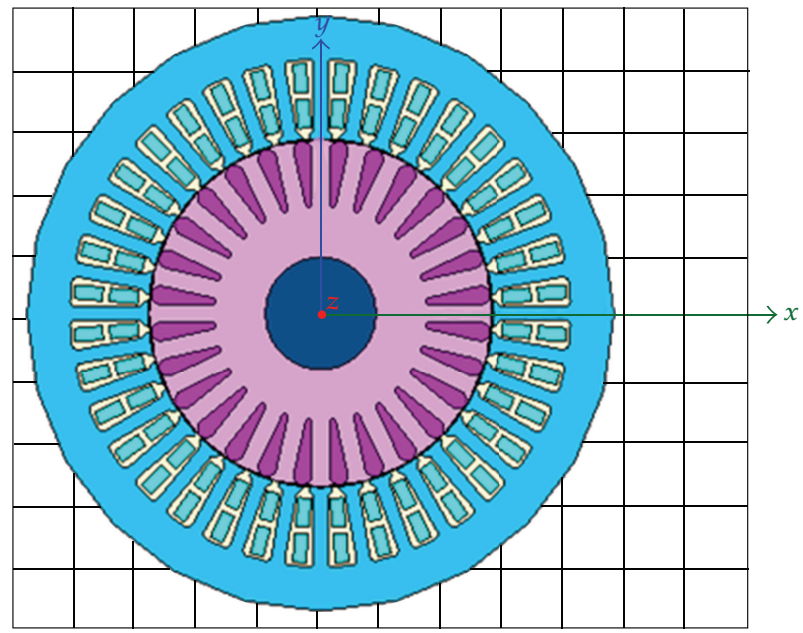

Figure 2: Simulated induction motor in Maxwell2D.

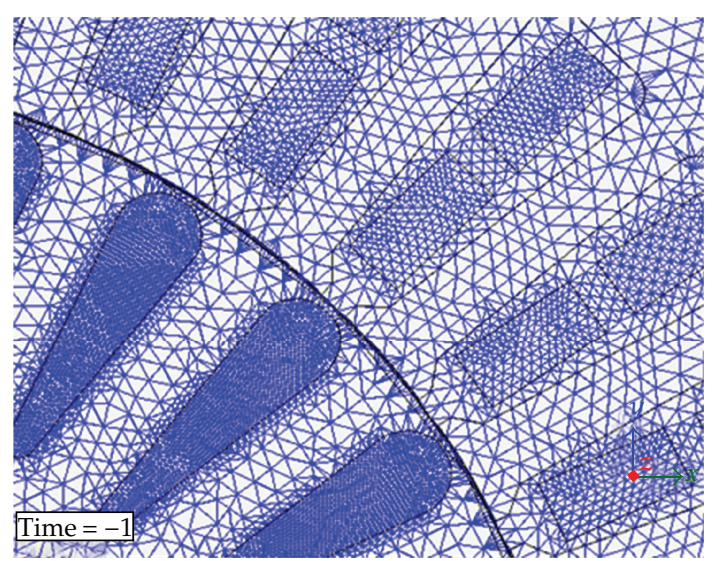

Figure 3: Mesh operation of the Maxwell2D for various parts of the IM (rotor slots, rotor core, stator slots, stator core, and air gap).

Asymmetry of the flux lines is due to (a) eddy currents, especially in the rotor slots, (b) severe changes of slip at the beginning of starting period, (c) elevated starting current, and (d) injected harmonic currents and saturation due to broken bars. Before analysing the problem, a series of small meshes on/in all parts of the machine is first created by FEM. Since there is a marked difference in the node networks of faulty and healthy bars, in case of the rotor bar failure, instantaneous analysis shortly after breakage in FEM becomes a complicated process. Hence, another supplementary program, such as MATLAB is needed to diagnose a broken bar failure immediately after bar breakage by modelling parameters like the corresponding outer rotor impedance. The faulty impedance includes resistance $\left(\Delta R_{\text {inc }}\right)$ and inductance $\left(\Delta L_{\text {inc }}\right)$ which are modelled in series in the rotor end as demonstrated in Figure 4.

Rotor bar fault is previously simulated [24, 25] using only one-phase resistance increase of the rotor, while neglecting the resulting inductance involved. The increased 


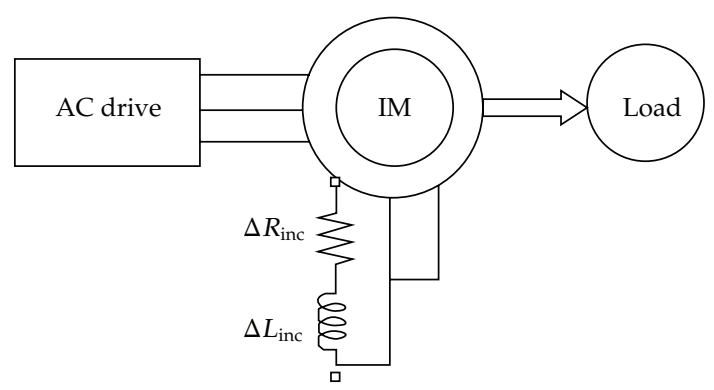

Figure 4: Schematic of a fault impedance insertion.

increment resistance corresponding to the broken bars to be considered in the external rotor circuit is computed as follow [25]:

$$
\Delta R_{\mathrm{inc}}=\frac{n}{N / 3-n} \frac{\left(2 N_{s}\right)^{2}}{N / 3} R_{b}
$$

where, $n$ is the number of contiguous broken bars, $N$ is rotor bar number, $N_{s}$ is turn number of stator phase winding, and $R_{b}$ is the rotor bar resistance. However, $\Delta R_{\text {inc }}$ alone is not accurate enough, and since computation of the broken bar resistance and inductance $\left(\Delta L_{\text {inc }}\right)$ is inherently a complicated process for which in general there is no reliable formula, genetic algorithm (GA) has been employed in this new method to obtain both inductance and resistance of the failed bars simultaneously as far as possible. The method for finding fault impedance is described in the next section.

\section{Genetic Algorithm and Proposed Objective Function}

GA is a global optimization and search technique motivated by the process of genetics and natural selection. In GA, a set of chromosomes (population) is led to evolve in a biased manner toward the fittest chromosomes based on special rules [26, 27]. The flowchart of the GA used in this work is presented in Figure 5. The goal is to search for an optimal solution while finding faulty broken bar impedance (resistance and inductance) and minimizing the objective function. To begin the GA process, an initial population size of 100 is randomly selected in the interval $[0,0.1]$. The faulty resistance and inductance that should be optimized is being fitted as chromosome. Hence,

$$
\text { Chromosome }=\left[\Delta R_{\text {inc }}, \Delta L_{\text {inc }}\right]
$$

MATLAB/SIMULINK is executed for all chromosomes to obtain the speed curve in the faulty condition, and each chromosome's worth is assessed by the objective function. It has to be pointed out that, for more accuracy and close relationship between real and simulated case, 


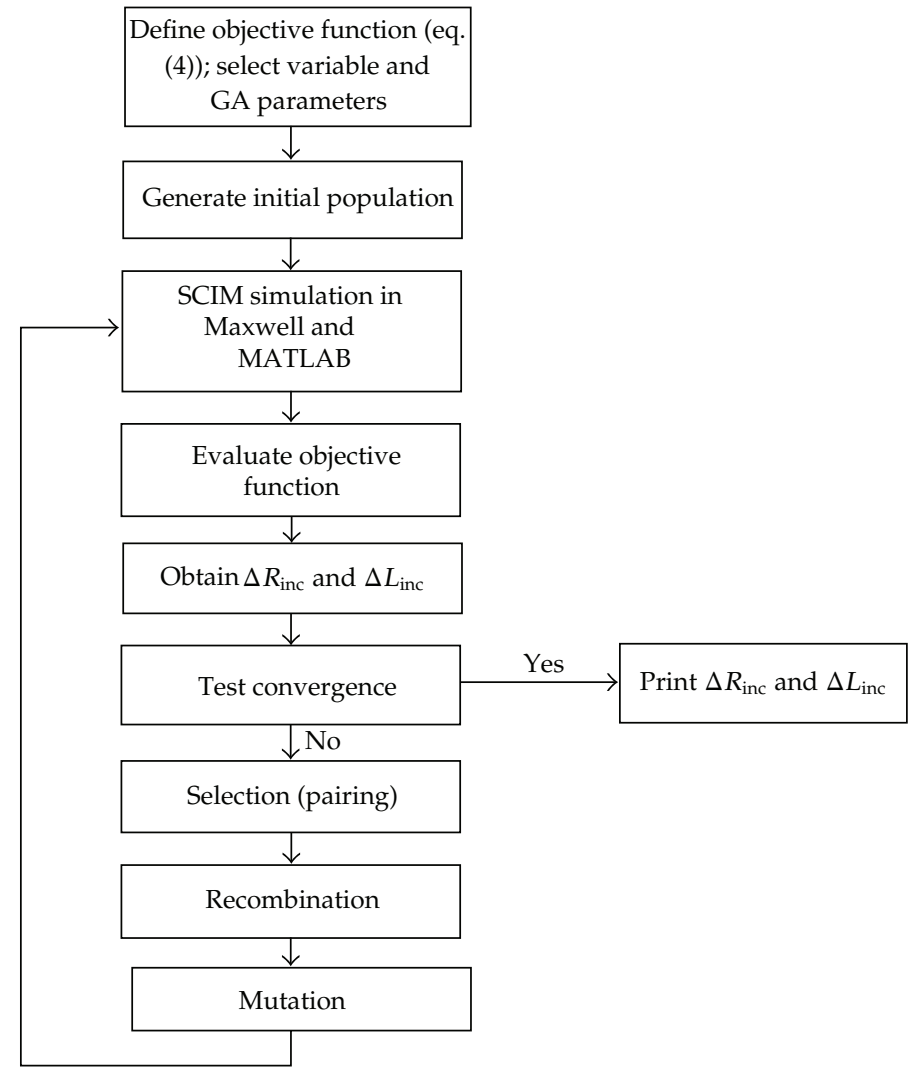

Figure 5: Flowchart of a GA for finding the fault impedance.

FEM is also used and the mutation rate of $20 \%$ is selected. The objective function is then defined as follow:

$$
\text { Objective Function }=\sum_{n=0}^{N} \frac{\left(\operatorname{speed}_{\mathrm{Max}}[n]-\operatorname{speed}_{\mathrm{Mat}}[n]\right)^{2}}{N},
$$

where speed $\mathrm{d}_{\text {Max }}$ is the output speed in FEM using MAXWELL software, speed $\mathrm{d}_{\text {Mat }}$ is the output speed by MATLAB, and $N$ is the total number of samples. Figure 6 shows a schematic diagram of the proposed method for finding the fault impedance. As illustrated in Figures 7 and 8, using the simulating setup for modelling validation in both healthy and faulty conditions, an analogous model is created in MATLAB/SIMULINK for both healthy and faulty cases, where faulty impedance is obtained by GA and the value of the resistance and inductance for one broken bar at rated condition is

$$
\Delta R_{\text {inc }}=0.175 \mathrm{Ohm}, \quad \Delta L_{\mathrm{inc}}=0.002 \mathrm{H} .
$$




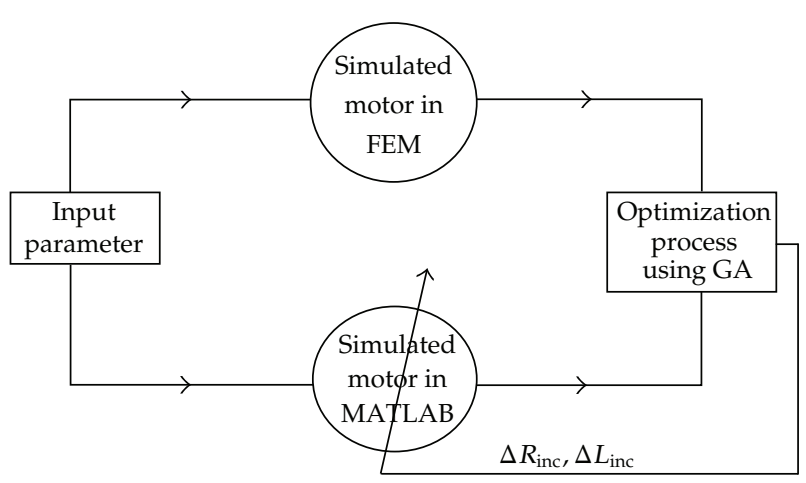

Figure 6: Structure of the proposed technique in this work.

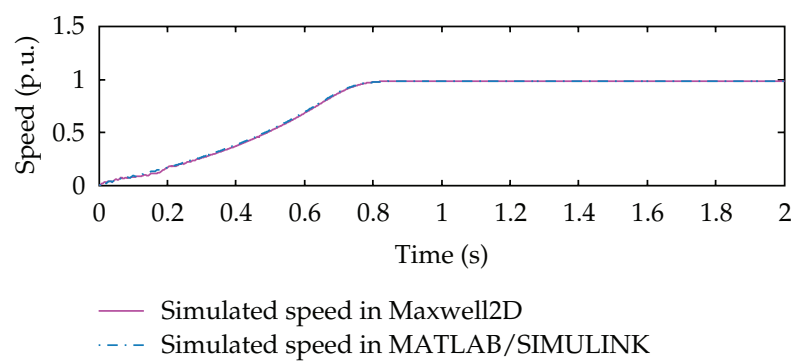

(a)

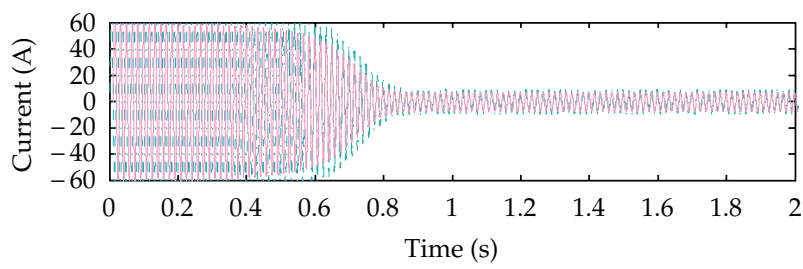

Simulated current in Maxwell2D

Simulated current in MATLAB/SIMULINK

(b)

Figure 7: Comparison of Maxwell2D and MATLAB curves in healthy condition (full-load operation).

\section{Discrete Wavelet Transform}

The excellent characteristic of the wavelet theory is that its frequency spectrum varies in time, which makes it suitable for analysing the nonstationary signals [28, 29]. Time evolution of the frequency components from the stator current signal depends on this specific phenomenon. For instance, evolution of the left sideband frequency, during the start-up for the case of rotor asymmetry, evolves in a particular way; when the machine is switched on, it is equal to the supply frequency. Later, when the slip equals 0.5 , it reaches $0 \mathrm{~Hz}$ and increases again close to the supply frequency, once the steady-state regime is achieved [18]. 


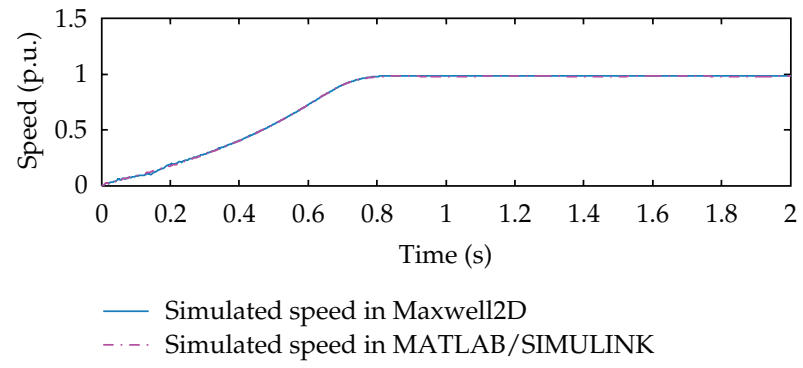

(a)

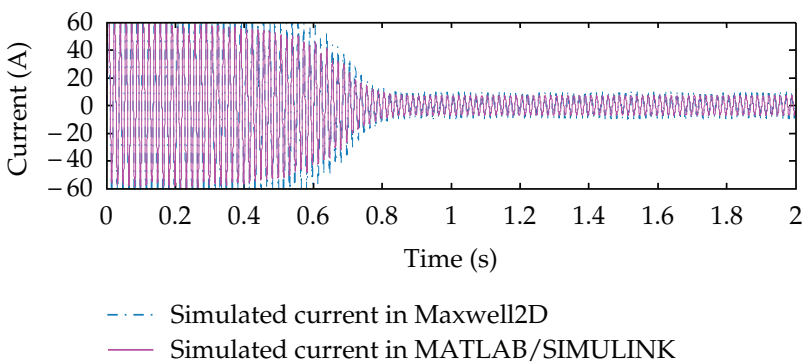

(b)

Figure 8: Comparison of Maxwell2D and MATLAB curves in motor with one broken bar (full-load operation).

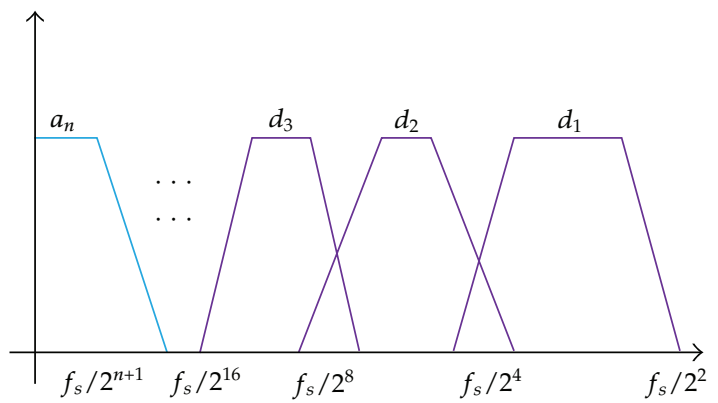

Figure 9: Frequency range of details and approximations in DWT.

The discrete wavelet transform (DWT) decomposed the sampled signal $x[n]$ as:

$$
X[n]=\sum_{j} a_{i_{0}, j} \varphi_{i_{0}, j}[n]+\sum_{i=i_{0}}^{I-1} \sum_{j} d_{i, j} \psi_{i, j}[n],
$$

where $\varphi[n]$ denotes the scaling function, $\psi[n]$ is the mother wavelet, and $\varphi_{i_{0}, j}[n]=$ $2^{i_{0} / 2} \varphi\left(2^{i_{0}} n-j\right)$ is the scaling function at a scale of $s=2^{i_{0}}$ shifted by $j$. Also, $\psi_{i, j}[n]=$ $2^{i / 2} \psi\left(2^{i} n-j\right)$ is the mother wavelet at a scale of $s=2^{i}$ shifted by $j, a_{i_{0}, j}$ are the approximation coefficients at a scale of $s=2^{i_{0}}$, and similarly $d_{i, j}$ are the detail coefficients at a scale of $s=2^{i}$ [30]. As shown in Figure 9, the frequency range of the approximation signal $a_{n}$, is in the interval $\left[0,2^{-(n+1)} f_{s}\right]$, and the detail $d_{j}$ contains the components whose frequencies 


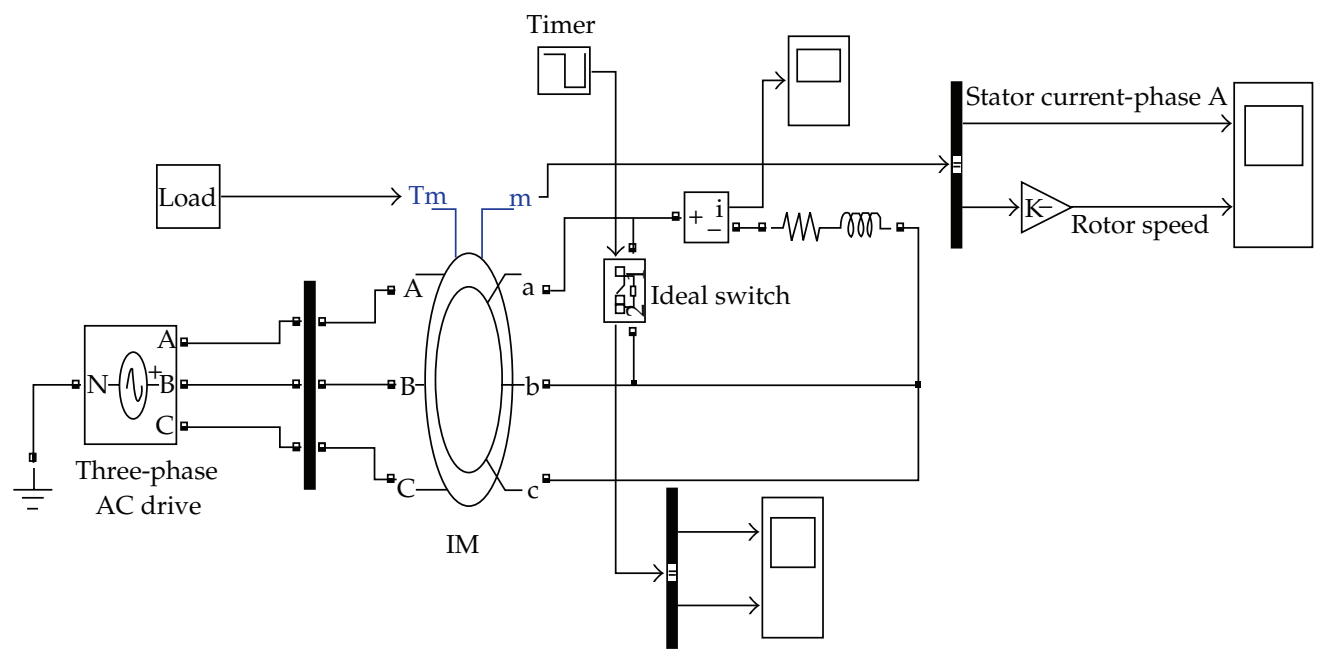

Figure 10: Implementing the proposed technique in MATLAB/SIMULINK.

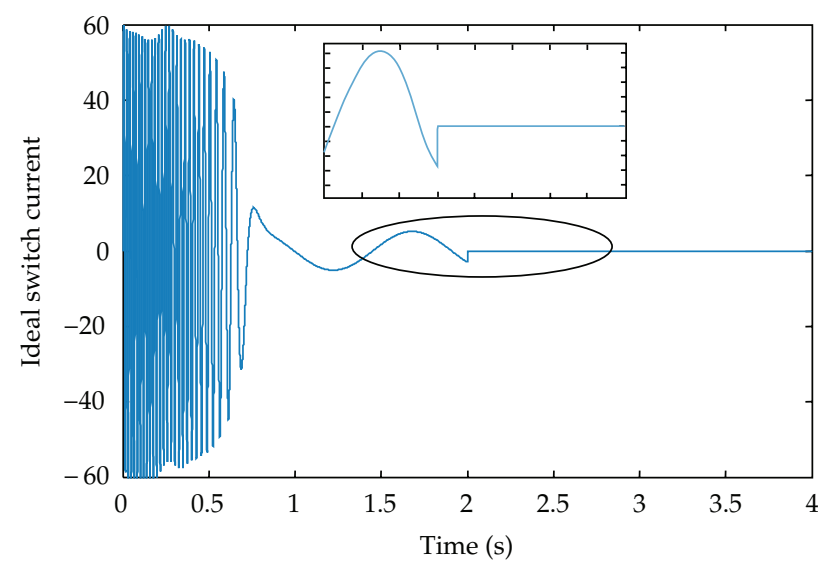

Figure 11: Ideal switch current simulated.

belong to the interval $\left[2^{-(j+1)} f_{s}, 2^{-j} f_{s}\right]$, where $f_{s}$ is the sampling frequency. To decrease the overlap between bands, a high-order wavelet (Daubechies 44) is used in this study to analyse the stator current signal immediately after bar breakage. DWT is able to locate accurately the frequencies and their exact time locations. Therefore, it can detect unforseen transient changes that might occur in any steady state due to its time-frequency decomposition.

\section{Simulation Result}

Simulation of SCIM for rotor bar failure detection was carried out to validate the proposed method. Figure 10 shows the schematic for detection of broken rotor bars in SCIM, shortly after bar breakage in MATLAB/SIMULINK. As can be seen, the broken bar failure is modelled by connecting impedance to the rotor end. To model the bar failure quickly after breakage, an ideal switch is used in the outer circuit of the rotor. Figure 11 shows the 
Mathematical Problems in Engineering
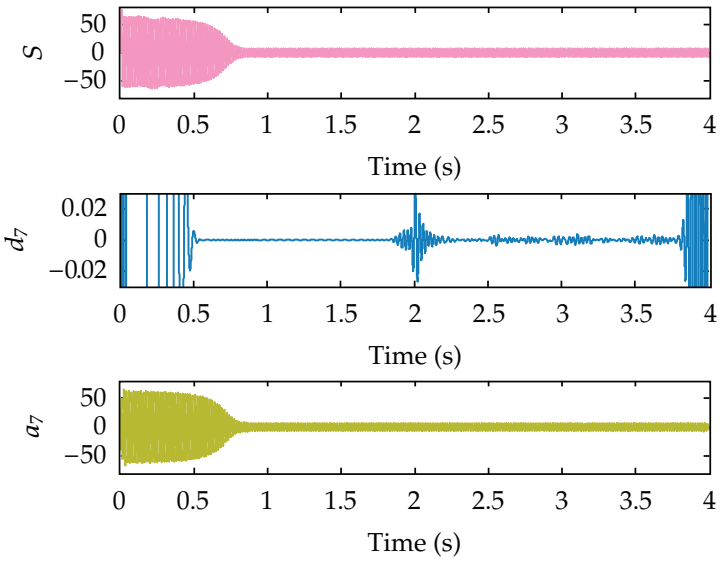

(a)
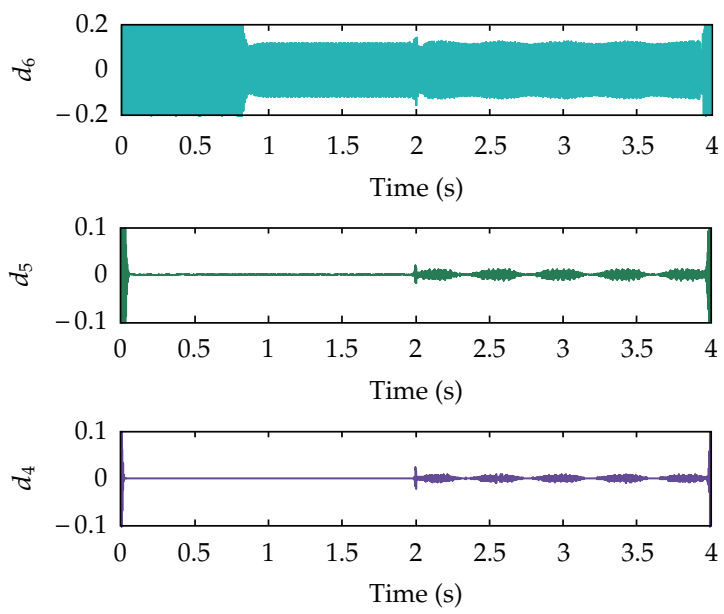

(b)
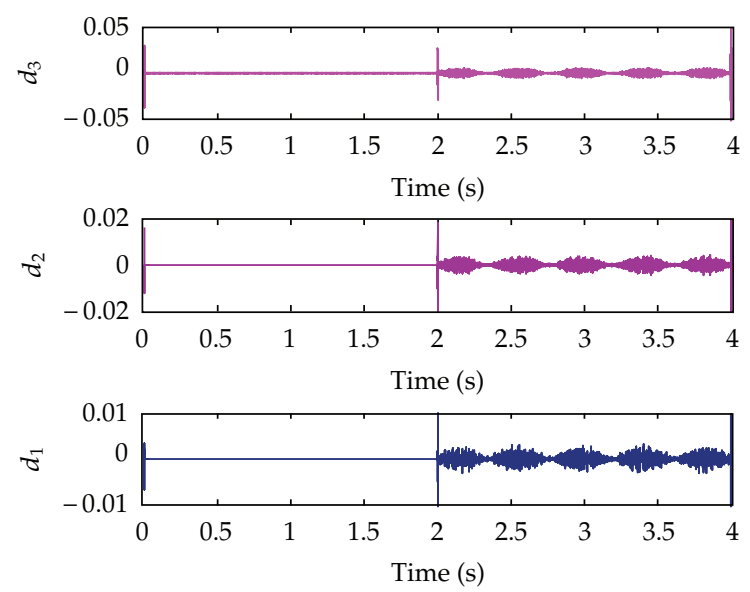

(c)

Figure 12: Wavelet decomposition of stator current signal for one broken rotor bar at rated condition. 
simulation result of the current curve of an ideal switch used for modelling bar failure during SCIM operation without having a significant effect on the motor performance. It is assumed that a bar is broken two seconds after the motor has reached steady-state operation.

Considering the advantages offered by DWT, in signal processing, it was used for stator current signal of the studied SCIM as depicted in Figure 12, in which healthy and broken bars conditions could be distinguished. Upon the occurrence of a fault, the variations in the DWT coefficients become higher than what they were prior to this incident. The seventh approximation, $\left(a_{7}\right)$, corresponding to the low-frequency components (below $60 \mathrm{~Hz}$ ), shows a meaningful variation following the fault. The peak variations after fault occurs are clearly seen in the sixth detail signal ( $d_{6}$ which corresponds to the frequency range between $78 \mathrm{~Hz}$ to $156 \mathrm{~Hz}$ ) and other detail signals. Much higher variations, representing the high-frequency content of the current signal, can be seen in details one to five $\left(d_{1}-d_{5}\right)$ which cover the frequency range between 156 to $5000 \mathrm{~Hz}$. Figure 12 shows how the harmonics appear in the wavelet coefficients after broken rotor bar fault.

\section{Conclusion}

Fault detection in incipient stages is important for control and protection of the SCIM. This paper aims to develop a diagnosis system of bar failure immediately after its breakage. By using FEM, GA, and MATLAB, an accurate model is simulated for fast fault detection using DWT to the stator current. Wavelet decomposition shows the meaningful variations in details numbered 1-5 and an approximation at level 7 (referred to as $a_{7}$ ), which correspond to the faulty bandwidth frequencies. Simulated start-up current DWT for full-load machine indicates that the breakage in one bar can be diagnosed correctly in its incipient stages. The simulation results indicate that the proposed technique is able to simulate accurately bar failure immediately after bar breakage.

\section{References}

[1] H. Su and K. T. Chong, "Induction machine condition monitoring using neural network modeling," IEEE Transactions on Industrial Electronics, vol. 54, no. 1, pp. 241-249, 2007.

[2] J. Cusido, L. Romeral, A. G. Espinosa, J. A. Ortega, and J. R. R. Ruiz, “On-line fault detection method for induction machines based on signal convolution," European Transactions on Electrical Power, vol. 21, no. 1, pp. 475-488, 2011.

[3] S. Choi, B. Akin, M. M. Rahimian, and H. A. Toliyat, “Implementation of a fault-diagnosis algorithm for induction machines based on advanced digital-signal-processing techniques," IEEE Transactions on Industrial Electronics, vol. 58, no. 3, Article ID 5456223, pp. 937-948, 2011.

[4] P. Zhang, Y. Du, T. G. Habetler, and B. Lu, "A survey of condition monitoring and protection methods for medium-voltage induction motors," IEEE Transactions on Industry Applications, vol. 47, no. 1, Article ID 5620974, pp. 34-46, 2011.

[5] S. Nandi and H. A. Toliyat, "Condition monitoring and fault diagnosis of electrical machines-a review," IEEE Transactions on Energy Conversion, vol. 20, no. 4, pp. 719-729, 2005.

[6] G. B. Kliman, R. A. Koegl, J. Stein, R. D. Endicott, and M. W. Madden, "Noninvasive detection of broken rotor bars in operating induction motors," IEEE Transactions on Energy Conversion, vol. 3, no. 4, pp. 873-879, 1988.

[7] N. M. Elkasabgy, A. R. Eastham, and G. E. Dawson, “Detection of broken bars in the cage rotor on an induction machine," IEEE Transactions on Industry Applications, vol. 28, no. 1, pp. 165-171, 1992.

[8] P. J. Rodriguez, A. Belahcen, and A. Arkkio, "Signatures of electrical faults in the force distribution and vibration pattern of induction motors," IEE Proceedings: Electric Power Applications, vol. 153, no. 4, pp. 523-529, 2006. 
[9] M. F. Cabanas, F. Pedrayes, M. R. González et al., “A new electronic instrument for the early detection of broken rotor bars in asynchronous motors working under arbitrary load conditions," in Proceedings of the 5th IEEE International Symposium on Diagnostics of Electric Machines, Power Electronics, and Drives (SDEMPED '05), pp. 29-34, Vienna, Austria, September 2005.

[10] F. Filippetti, G. Franceschini, C. Tassoni, and P. Vas, “AI techniques in induction machines diagnosis including the speed ripple effect," IEEE Transactions on Industry Applications, vol. 34, no. 1, pp. 98-108, 1998.

[11] H. Douglas, P. Pillay, and A. K. Ziarani, "A new algorithm for transient motor current signature analysis using wavelets," IEEE Transactions on Industry Applications, vol. 40, no. 5, pp. 1361-1368, 2004.

[12] S. Hedayati-Kia, H. Henao, and G. A. Capolino, "A high-resolution frequency estimation method for three-phase induction machine fault detection," IEEE Transactions on Industrial Electronics, vol. 54, no. 4, pp. 2305-2314, 2007.

[13] R. R. Schoen and T. G. Habetier, "Evaluation and implementation of a system to eliminate arbitrary load effects in current-based monitoring of induction machines," IEEE Transactions on Industry Applications, vol. 33, no. 6, pp. 1571-1577, 1997.

[14] B. Xu, L. Sun, and H. Ren, "A new criterion for the quantification of broken rotor bars in induction motors," IEEE Transactions on Energy Conversion, vol. 25, no. 1, Article ID 5340658, pp. 100-106, 2010.

[15] C. Bruzzese, O. Honorati, E. Santini, and D. Seiunnache, "New rotor fault indicators for squirrel cage induction motors," in Proceedings of the 41st IEEE Industry Applications Society Annual Meeting(IAS '06), vol. 1, pp. 1264-1269, Tampa, Fla, USA, 2006.

[16] R. Burnett, J. F. Watson, and S. Elder, "The application of modern signal processing techniques to rotor fault detection and location within three phase induction motors," Eur. Signal Process. J., vol. 49, pp. 426-431, 1996.

[17] J. F. Watson and N. C. Paterson, "Improved techniques for rotor fault detection in three-phase induction motors," in Proceedings of the 33rd IEEE Industry Applications Society Annual Meeting (IAS '98), vol. 1, pp. 271-277, October 1998.

[18] M. Riera-Guasp, J. A. Antonino-Daviu, J. Roger-Folch, and P. M. M. Palomares, "The use of the wavelet approximation signal as a tool for the diagnosis of rotor bar failures," IEEE Transactions on Industry Applications, vol. 44, no. 3, pp. 716-726, 2008.

[19] J. A. Antonino-Daviu, M. Riera-Guasp, J. R. Folch, and M. P. M. Palomares, "Validation of a new method for the diagnosis of rotor bar failures via wavelet transform in industrial induction machines," IEEE Transactions on Industry Applications, vol. 42, no. 4, pp. 990-996, 2006.

[20] J. Faiz, B. M. Ebrahimi, and M. B. B. Sharifian, "Time stepping finite element analysis of broken bars fault in a three-phase squirrel-cage induction motor," Progress in Electromagnetics Research, vol. 68, pp. 53-70, 2007.

[21] J. Faiz and B. M. Ebrahimi, "Locating rotor broken bars in induction motors using finite element method," Energy Conversion and Management, vol. 50, no. 1, pp. 125-131, 2009.

[22] Ansoft Corporation, “Maxwell2D," Ver. 13, 2010, http://www.ansoft.com/products/em/max2d.

[23] L. Wu, Separating load torque oscillation and rotor faults in stator current based-induction motor condition monitoring, Ph.D. thesis, Georgia Institute of Technology, May 2007.

[24] D. Kostic-Perovic, P. J. Unsworth, and M. Arkan, "Analysis of a SVAF rotor fault index," in Proceedings of the IEEE International Symposium on Diagnostics for Electrical Machines, Power Electronics and Drives (SDEMPED '01), pp. 513-516, Grado, Italy, September 2001.

[25] A. Bellini, F. Filippetti, G. Franceschini, C. Tassoni, and G. B. Kliman, "Quantitative evaluation of induction motor broken bars by means of electrical signature analysis," IEEE Transactions on Industry Applications, vol. 37, no. 5, pp. 1248-1255, 2001.

[26] R. L. Haupt and S. E. Haupt, Practical Genetic Algorithms, John Wiley \& Sons, New York, NY, USA, 2nd edition, 2004.

[27] H. Razik, M. B. D. R. Corrêa, and E. R. C. da Silva, “A novel monitoring of load level and broken bar fault severity applied to squirrel-cage induction motors using a genetic algorithm," IEEE Transactions on Industrial Electronics, vol. 56, no. 11, pp. 4615-4626, 2009.

[28] F. Haghjoo and M. Shartash, "Wavelet transform based decomposition and reconstruction for online PD detection and measurement. Part I: narrow band components decomposition," European Transactions on Electrical Power, vol. 20, no. 7, pp. 901-9014, 2010.

[29] S. H. Kia, H. Henao, and G. A. Capolino, "Diagnosis of broken-bar fault in induction machines using discrete wavelet transform without slip estimation," IEEE Transactions on Industry Applications, vol. 45, no. 4, pp. 1395-1404, 2009. 
[30] J. Cusidó, L. Romeral, J. A. Ortega, J. A. Rosero, and A. G. Espinosa, "Fault detection in induction machines using power spectral density in wavelet decomposition," IEEE Transactions on Industrial Electronics, vol. 55, no. 2, pp. 633-643, 2008. 


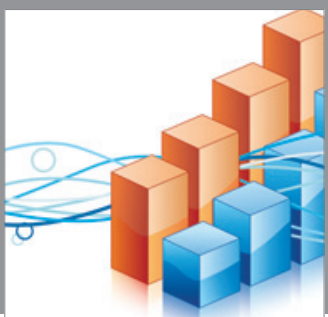

Advances in

Operations Research

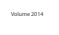

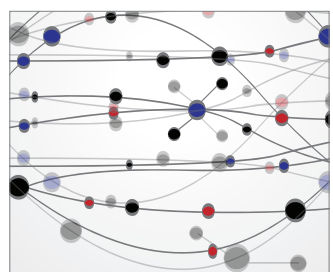

\section{The Scientific} World Journal
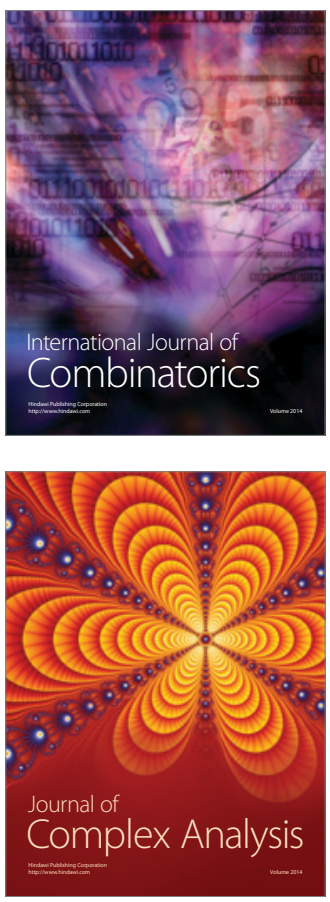

International Journal of

Mathematics and

Mathematical

Sciences
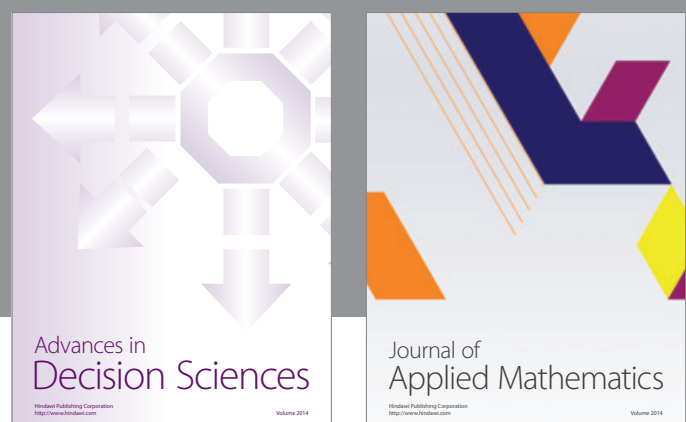

Journal of

Applied Mathematics
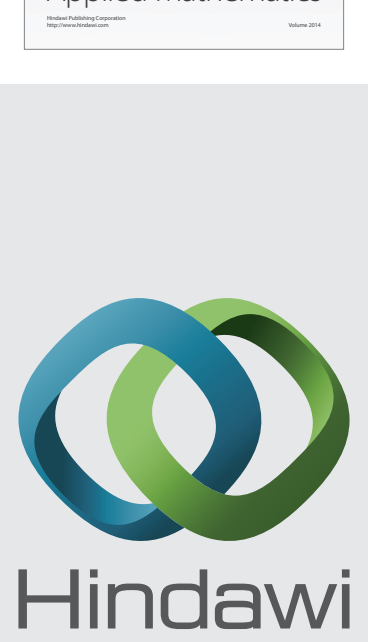

Submit your manuscripts at http://www.hindawi.com
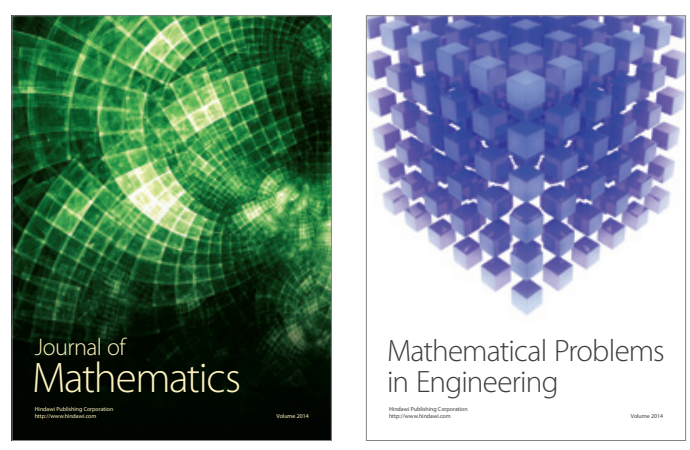

Mathematical Problems in Engineering
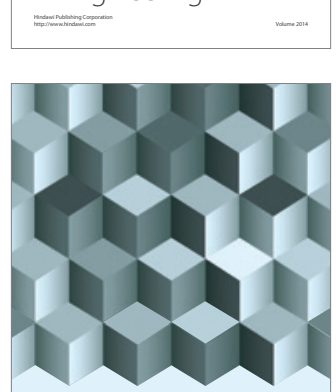

Journal of

Function Spaces
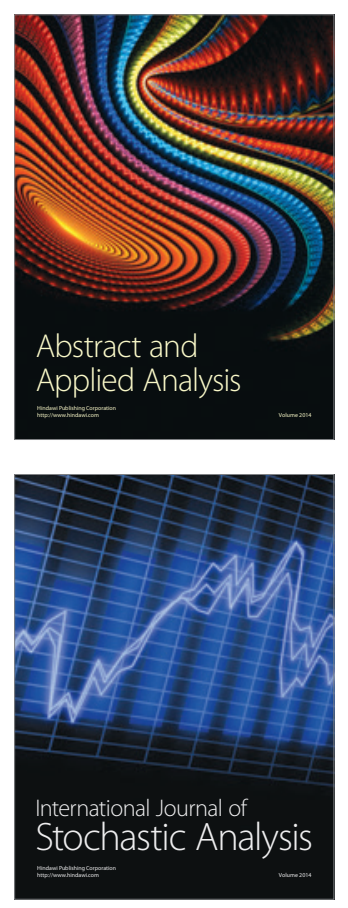

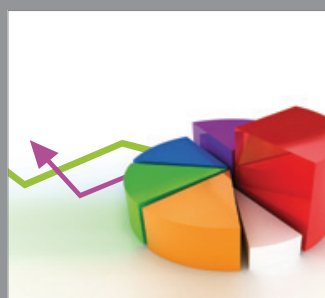

ournal of

Probability and Statistics

Promensencen
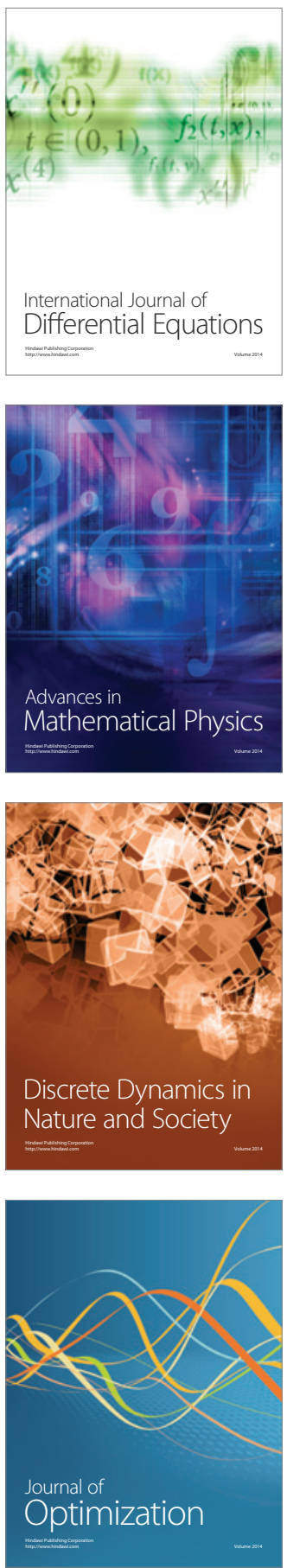